\title{
THE EDUCATIONAL SITUATIONS OF BILINGUAL STUDENTS WITH LEARNING DISABILITIES IN HAND IN HAND SCHOOLS IN JERUSALEM
}

\begin{abstract}
Aвstract. Perelmuter Idit, The Educational Situations of Bilingual Students with Learning Disabilities in Hand in Hand Schools in Jerusalem [Sytuacja edukacyjna dwujęzycznych uczniów z trudnościami w uczeniu się w szkole Hand in Hand w Jerozolimie]. Studia Edukacyjne nr 51, 2018, Poznań 2018, pp. 515-522. Adam Mickiewicz University Press. ISSN 1233-6688. DOI: 10.14746/se.2018.51.32
\end{abstract}

This article will address the educational situations with which bilingual students who have learning disabilities cope in the education system and in the bilingual schools of Hand in Hand, an association which was established to promote and develop a shared society for Arabs and Jews in Israel. In addition, it will describe the difficulties of the learning-disabled bilingual students and how they impact upon the student. The first part will present the educational concept of Hand in Hand and the reality of the bilingual school in Jerusalem in particular. The second part will describe educational situations in which bilingual students who have learning disabilities cope in the bilingual school of the Hand in Hand Association. Furthermore, it will address the difficulties of these students in the school. The third part focuses upon the relationship between the ecological model of Bronfenbrenner and neuro-developmental theory and the educational situations of learning-disabled bilingual students, with an emphasis on their immediate environment (the educational situations described in the article are taken from professional experience in my work in the bilingual school in Jerusalem as an inclusion teacher for learning-disabled bilingual students both in the elementary and middle schools).

Key words: bilingual students, learning disabilities, educational system, Jews and Arabs, Israel

Hand in Hand was established with the goal of promoting and developing an egalitarian society for Arabs and Jews in Israel. The Hand in Hand Association offers a new model of bilingual education, in which both Hebrew and Arabic are the languages of instruction in schools and are accorded equal status, with Jews and Arabs learning together both languages. The basic idea behind the initiative is to create a bilingual educational environment with respect and equality for both groups, enabling the members of the community to develop continuous and equal relationships of cooperation, coexistence, and education for peace. The schools which are part of Hand in Hand Asso- 
ciation emphasize the symmetry between the two languages in every aspect of teaching. Two teachers, an Arab and a Jew, together conduct most of the lessons. Two principals, an Arab and a Jew, together stand at the head of the school. ${ }^{1}$ The Max Rayne Hand in Hand School was the first of the educational institutions of the Hand in Hand Association. Today more than 550 students, from pre-kindergarten to twelfth grade, study in the school. Attending the school are Muslim, Jewish, Christian, Druse, and Armenian students, both religious and secular. Hebrew and Arabic are given equal status in the school, because of the perception that the language is not only an essential means for reciprocal communication but also a central element in every person's culture. The aspiration is that all children will achieve the ability to learn, write, and express themselves in a second language in a way that will not be less than that their first language. ${ }^{2}$ Hebrew speaking students learn Hebrew as a first language and Arabic as a second language. Arabic speaking students learn Arabic as their first language and Hebrew as their second language. The teachers in the school teach in their native language.

The bilingual students with learning disabilities in the bilingual school are defined as special needs students who learn in the regular education system in Israel. In other words, they are students whose eligibility to be included in a program that integrates special needs students within the school system has been approved by the school committee. These students are given support by the special education staff in the school that specializes in the care of students with different disorders, according to the student's needs and taking into account the resources available in the school. For every such student an individualized education plan (IEP) is created, with aim of allowing the student to go on to learn in the regular education framework and to integrate within it. ${ }^{3}$

In accordance with the school's mandate, these students also study a first language and a second language in the school, when for the most part they learn their native language as a first language. In cases where there are two or more languages in the home, the parents must choose the first language for their child. However, there are cases in which the parents, the educational staff, and the student choose together the first language that the child will learn in the school in accordance with the student's personal background. The bilingual students with learning disabilities come from different and diverse language backgrounds. Some of the children speak a native language at home (which may be one or more) that differs from the languages in the bi-lingual

\footnotetext{
${ }^{1}$ S. Amara, The Hand-in-Hand Bilingual Education Model: Vision and Challenges, [in:] Issues in Language Teaching in Israel, Eds. S. Dunitze-Schmidt, A. Inbar-Loria, Tel-Aviv 2014, p. 73-76.

2 Hand in Hand, Hand in Hand. [Online] Retrieved on 02.10.2017 from: http:/ / www.handinhandk12.org/

3 Special Education Law, 1988; Director General's Circular, 2007, 68/3(d); Director General's Circular, 2014, 5(a).
} 
schools; some of the students speak two languages at home, with one language learned in school (Hebrew or Arabic), and there are students who speak only one language at home, Hebrew or Arabic.

It is also apparent that the students come from a spectrum of cultural backgrounds. The first group of students consists of the children of parents of the same religion (for instance, Jews, Muslim, or Christians). The second group of students consists of children of "mixed couples", or in other words, each parent has a different religion, for instance a Jewish mother and a Muslim father or a Christian mother and a Muslim father, and so forth. There are, in addition, significant differentiations related to the students' cultural background, which may be expressed among children whose parents come from the same religion and among children of "mixed couples". The differences are as follows: In the first instance, at least one of the child's parents has immigrated to Israel from his country of origin or both the parents have immigrated to Israel, for example, children whose parents have come to Israel from Ethiopia. In the second instance, the child's parents are of differing civil status, for instance a child of Arab parents when one parent has Israeli citizenship and the other parent has a work permit. The third instance is the residential environment of the extended family (which includes the grandparents, the aunts and uncles, etc.) and addresses two possible situations. Either the child's extended family lives in part in the territory of the Palestinian Authority and not in the territory of the State of Israel or the child's extended family lives in another country, which is usually the country from which the child's parents immigrated to Israel.

As previously mentioned, bilingual students with learning disabilities learn together with a group of children for the most part with special education teachers in their primary language for 2-3 hours a week. Simultaneously, they continue to learn in the framework of the class their first language. The assumption at the basis of this perception is that it is necessary to establish their learning skills so that they will achieve mastery of reading and writing, at least in one language, since it is difficult for these students to acquire reading and writing both in Hebrew and in Arabic. In addition, they continue to learn the second language within the framework of the class. Moreover, it seems that most bilingual students with learning disabilities cope with assorted difficulties, including:

1. Academic difficulties

2. Difficulties resulting from or concomitant with academic difficulties, such as attention and focus difficulties, emotional and behavioral difficulties, social difficulties, etc.

3. Difficulties associated with their cultural background, for instance, among "mixed students", whose religious identity is composed of two different religions. This can be seen, for example, in a "mixed student" whose mother is Jewish and whose father is Arab, whose life straddles these two 
religions (Judaism and Islam) and who will experience considerable tension and complicated relationships as a result of the fluctuating political situation in Israel ${ }^{4}$ and the Arab-Jewish conflict. ${ }^{5}$

4. Difficulties related to their personal background, for instance, family status (married/divorced/separated parents).

It can be seen that the educational situations of students with learning disabilities and the difficulties with which they cope are related, first and foremost, to the students themselves. In addition, they are related also to their immediate environment, which includes their parents, the school, and their classmates. To attempt to understand the educational situation of learningdisabled students and their implications for the student, the parents, and the school, two theoretical perceptions will be presented, with the first addressing the ecological model and the second the neurodevelopmental approach.

Bronfenbrenner's ecological model ${ }^{6}$ places the child and his personal characteristics at the center of the ecosystem that surrounds him. The child's characteristics include his temperament, gender, age, and other attributes related to his developmental potential (such as cognitive ability and special talents). In addition to these personal characteristics, the child's ecological system includes four other systems, the microsystem, the mesosystem, the exosystem, the macrosystem and the chronosystem. The microsystem is the immediate environment in which the child lives and is raised. This environment directly influences the child's development and is influenced by it. It includes the various personalities with which the child interacts in daily contact and their personal characteristics - parents, siblings, educators, etc. The mesosystem addresses all the reciprocal relationships in the microsystem - the relationship between the father and the mother, between the parents and the teacher, etc. The exosystem addresses the child's further ranging environment, in which all the figures in the child's immediate environment live and act. The outside system influences the child indirectly and includes, for instance, the characteristics of the neighborhood where the child lives, the social services in his neighborhood, the local politics, and so on. The macrosystem is all-inclusive and covers geopolitical data, the characteristics of the culture, the society, the government regime, and even the economy in which all the other systems exist and in which the child grew up. The chronosystem addresses the dimen-

\footnotetext{
${ }^{4}$ W.L Cleveland, M. Bunton, A History of the Modern Middle East, 6th Ed., 2016; L. Fawcett, International Relations of the Middle East, 6th Ed., 2016.

${ }^{5}$ M. Bar-On, Independence in the Shadow of Wars - Six Reviews in the History of the Israeli-Arab Conflict, 2014; A. Rabinovitz, The Distancing Horizon: Israel, the Arabs, and the Middle East, 19482012, Or Yehuda 2012; A. Shavit, A. Winter, My Enemy, My Teacher: Zionism and Israel in the Doctrine of Islamists and Arab Liberals, Bnei Brak 2013.

${ }^{6}$ U. Bronfenbrenner, The Ecology of Human Development, Cambridge 1979.
} 
sion of the time in which all the other systems exist and interact, with all the changes that occur in them over time. ${ }^{7}$

Hence, the model describes a child who develops in an environment that in essence is a network of the systems that are mutually dependent and which impact upon one another, ${ }^{8}$ so that the influence is both ways. In other words, the systems influence the child and are influenced by him. Therefore, according to the statements above, the school, the parents, the family, and the friends of the learning-disabled bilingual child are defined according to the ecological model as the child's near environment, or as Bronfenbrenner ${ }^{9}$ called the microsystem, while the reciprocal relations between the parents of the learning-disabled bilingual child and the school staff, between the child's father and mother, between the members of the educational staff and the children in the class are, according to this model, related to the mesosystem. In addition, the place of residence of the learning-disabled bilingual child, the social services in the region of his residence, and the situation of local politics refer to the exosystem, while the geopolitical situation in Israel, the education system in Israel, the culture, the economy, and society link to the macrosystem. Moreover, it can be said that these systems impact upon and are influenced by the learning-disabled bilingual child.

The Learning-Disabled Bilingual Child according to the Bronfenbrenner Model

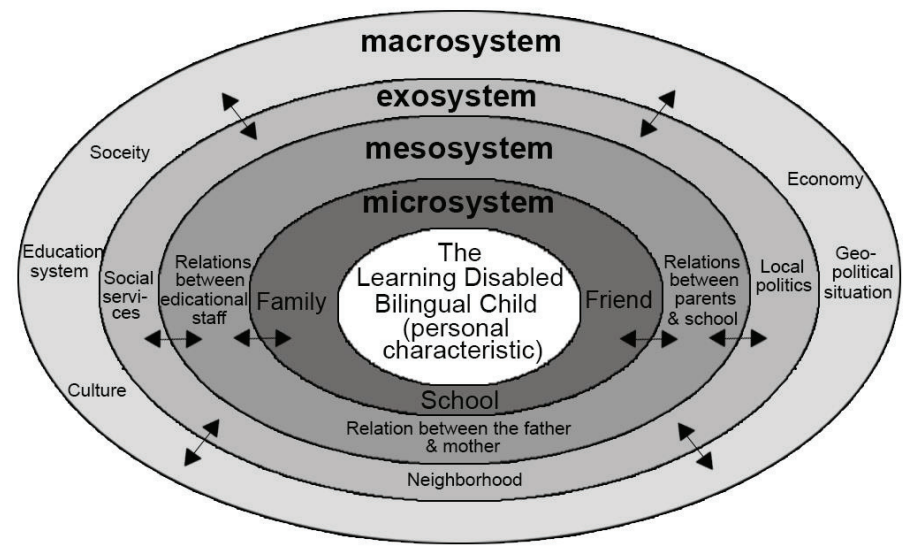

${ }^{7}$ U. Bronfenbrenner, Making Human Beings Human: Bioecological Perspectives on Human Development, Thousand Oaks 2005.

${ }^{8}$ U. Bronfenbrenner, The Bioecological Model from a Life Course Perspective: Reflections of a Participant Observer, [in:] Examining Lives in Context: Perspective on the Ecology of Human Development, Eds. P. Moen, G.H. Elder, K. Luscher, Washington 1995, p. 599-618.

${ }_{9}$ U. Bronfenbrenner, The Ecology of Human Development. 
The neurodevelopmental approach focuses on research of the reciprocal influences between genetic components and environmental influences. ${ }^{10}$ The brain is perceived as a system composed of neurological subsystems that are found in reciprocal relations and have a mutual influence on every subsystem and between the subsystems and in unending reciprocal relations between them and their environment. The neurological system develops and changes over the course of a person's life, although at different rates and varying ways over in different periods. ${ }^{11}$ In other words, what is significant is not only the difficulties in functioning but also the reciprocal relationships between the subsystems and the reciprocal relationships between the systems and their environment. ${ }^{12} \mathrm{Mo}-$ reover, the neurodevelopmental perception also emphasizes the importance of reciprocal relations between the neurological systems and the subsystems and the reciprocal relations between the systems and their environment. Margalit and Tur-Kaspa ${ }^{13}$ present a multidimensional ecological neurodevelopmental model that indicates reciprocal relations between the individual's characteristics, with his difficulties and strengths, and the characteristics of the environment, the family, and the educational environment and these reciprocal relationships contribute to the prediction or understanding of the performance and difficulties of learning-disabled students in different periods. According to this model, relations between the individual and the environment are not static but constantly dynamic; they are reciprocal and not one-way, and they share a mutual dependence on one another. The model emphasizes the reciprocal relationships between the different variables that influence an individual's performance in all areas of development. In addition, the model is based on the empowerment approach, as an alternative approach that does not negate the recognition of the importance of the assessment of specific deficiencies, but emphasizes the importance accorded to the cultivation of effective coping mechanism, alongside the recognition and handling of the individual's difficulties.

In other words, in the context of children with learning disabilities, they emphasize the importance of reciprocal relations between the child and his environment in the process of the development and focus on the influence of the family and the school on the learning-disabled students' development and simultaneously the students' influence on their environment ${ }^{14}$. Hence, it can be concluded that according to the neurodevelopmental approach and the model

${ }^{10}$ M. Margalit, Learning Disabilities: Neuro-Developmental Model after 15 Years, a Meeting for Social-Educational Work, Tel-Aviv 2014.

${ }_{11}$ M. Margalit, H. Tur-Kaspa, Learning Disabilities: A Multidimensional Neuro-Developmental Model, Psychology, 1998, 7(1), p. 64-76.

12 M. Margalit, Learning Disabilities.

${ }_{13}$ M. Margalit, H. Tur-Kaspa, Learning Disabilities: A Multidimensional Neuro-Developmental Model.

${ }^{14}$ M. Margalit, Learning Disability in the Classroom: Educational Dilemmas in a New Reality, Mofet Institute, 2000. 
developed by Margalit and Tur-Kaspa ${ }^{15}$ there are mutual reciprocal relations between the bilingual children with learning disabilities and their families and their schools in the process of their development. In other words, the family and the school influence the development of learning-disabled bilingual children and are, concurrently, influenced by it. In addition, these approaches emphasize the importance of reciprocal relationships between the different factors that surround learning-disabled bilingual students, for instance, the relations between the parents and the school staff. Moreover, it appears that according to the model of Margalit and Tur-Kaspa ${ }^{16}$ there are reciprocal links between the personal characteristics of learning-disabled bilingual students, their strengths and their weaknesses, and their families and their schools. Relations such as these can facilitate the prediction of difficulties, or help to understand the difficulties that these studies are undergoing, and promote an understanding of their performance at school. In addition, the relations are dynamic and not one-way and depend on one another. Moreover, the reciprocal relations between the factors surrounding them influence the performance of learning-disabled bilingual students in different areas, such as memory, morphology, and so on.

\section{The Learning-Disabled Bilingual Child according to the Margalit \& Tur-Kaspa Model}

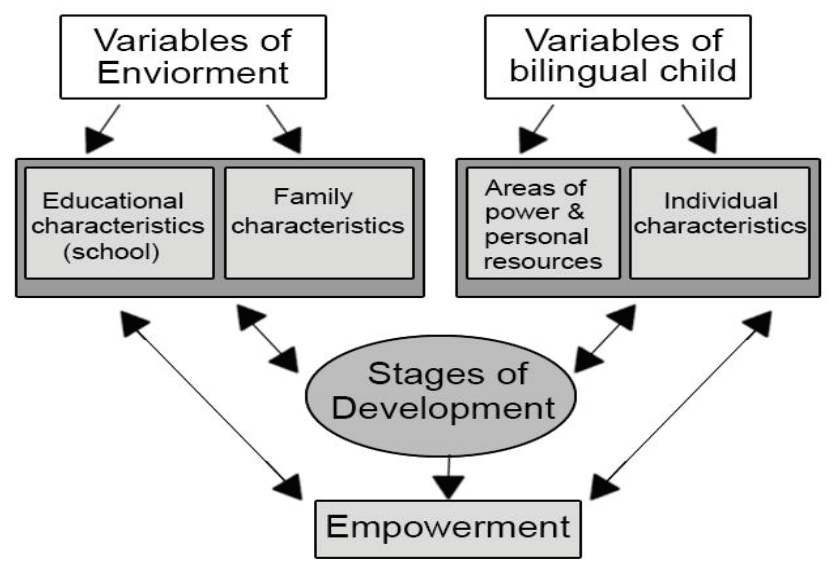

Therefore, it can be said that according to the model of Bronfenbrenner ${ }^{17}$ the educational situations of learning-disabled bilingual students in a bilingual school, as presented previously, address the four systems - the microsystem, the mesosystem, the exosystem, and the macrosystem and with a focus

${ }_{15}$ M. Margalit, H. Tur-Kaspa, Learning Disabilities: A Multidimensional Neuro-Developmental Model, p. 64-76.

16 Ibidem.

${ }^{17}$ U. Bronfenbrenner, The Ecology of Human Development. 
primarily on the microsystem, the child's closest environment, composed of the family and the school, and the mesosystem, the reciprocal relations between the individuals who surround the child. Moreover, according to the neurodevelopmental theory and the model of Margalit and Tur-Kaspa, ${ }^{18}$ it is possible to see that the educational situations of learning-disabled bilingual students in the bilingual school focus especially on the influence of the school and the parents on the learning-disabled bilingual students' development and in parallel on the influence of these children's developmental situation on the school and their parents. In addition, they emphasize the influence of reciprocal relations between the various factors that surround learning-disabled bilingual students, and their impact on their functioning.

\section{BIBLIOGRAPHY}

Amara S., The Hand-in-Hand Bilingual Education Model: Vision and Challenges, [in:] Issues in Language Teaching in Israel, Eds. S. Dunitze-Schmidt, A. Inbar-Loria, Mofet Institute, Tel-Aviv 2014.

Bar-On M., Independence in the Shadow of Wars - Six Reviews in the History of the Israeli-Arab Conflict, Resling Press, 2014.

Bronfenbrenner U., The Ecology of Human Development, Harvard University Press, Cambridge 1979.

Bronfenbrenner U., The Bioecological Model from a Life Course Perspective: Reflections of a Participant Observer, [in:] Examining Lives in Context: Perspective on the Ecology of Human Development, Eds. P. Moen, G.H. Elder, K. Luscher, American Psychological Association, Washington 1995.

Bronfenbrenner U., Making Human Beings Human: Bioecological Perspectives on Human Development, Sage Publications, Thousand Oaks 2005.

Cleveland W.L., Bunton M., A History of the Modern Middle East, $6^{\text {th }}$ Ed., Westview Press, 2016. Fawcett L., International Relations of the Middle East, $6^{\text {th }}$ Ed., Oxford University Press, 2016.

Hand in Hand, Hand in Hand. [Online] Retrieved on 02.10.2017 from: http:/ /www.handinhandk12.org/

Margalit M., Learning Disability in the Classroom: Educational Dilemmas in a New Reality, Mofet Institute, 2000.

Margalit M., Tur-Kaspa H., Learning Disabilities: A Multidimensional Neuro-Developmental Model, Psychology, 1998, 7(1).

Margalit M., Learning Disabilities: Neuro-Developmental Model after 15 Years, a Meeting for Social-Educational Work, Tel-Aviv University, Tel-Aviv 2014.

Ministry of Education, Director General's Circular 2007, 58/3(d).

Ministry of Education, Director General's Circular 2014, 5(a).

Rabinovitz A., The Distancing Horizon: Israel, the Arabs, and the Middle East, 1948-2012, Dvir Press, Or Yehuda 2012.

Shavit A., Winter A., My Enemy, My Teacher: Zionism and Israel in the Doctrine of Islamists and Arab Liberals, HaKibbutz HaMeuchad Press, Bnei Brak 2013.

State of Israel, Special Education Law, 1988.

18 M. Margalit, H. Tur-Kaspa, Learning Disabilities: A Multidimensional Neuro-Developmental Model, p. 64-76. 